\title{
COVID-19 pandemic and the use of tele-health by pediatricians and pediatric Post graduate residents
}

\author{
Tehreem Fatima ${ }^{a}$, Zaib Nasir ${ }^{\mathrm{b}}$, AbdulAhad Jamshaid ${ }^{\mathrm{c}}$, Hina Ayesha ${ }^{\mathrm{d}}$ \\ a Senior Registrar Department of Pediatrics, Children Hospital \& Institute of Child Health, Faisalabad \\ ${ }^{\mathrm{b} S}$ Senior Registrar Department of Pediatrics, Mayo Hospital, Lahore. \\ 'Senior Registrar Department of Pediatric Nephrology, Children Hospital \& Institute of Child Health, Lahore. \\ 'Professor Department of Pediatrics, Faisalabad Medical University and Dean Children Hospital \& Institute of Child \\ Health, Faisalabad. \\ *Corresponding Author's e-mail: tehreem_fatima_14@hotmail.com
}

\section{ABSTRACT}

BACKGROUND \& OBJECTIVE: During the COVID-19 pandemic, burden on healthcare facilities has increased worldwide; which has led to acceptance of the 'telehealth services' by the pediatricians. Objective of this study was to determine the impact on frequency of use of tele-health services by pediatricians during the COVID-19 pandemic; and to determine the factors promoting and preventing the use of tele-health services by pediatricians.

METHODOLOGY: This descriptive cross-sectional study was carried out from August 2020 to January 2021 among the pediatricians of Children Hospital Faisalabad and other affiliated hospitals of Faisalabad Medical University, Pakistan. An e-questionnaire was circulated among 357 pediatricians, which was filled and submitted by 114 pediatricians online. Demographic details and other data were collected and analyzed by SPSS v.20. P-value $<0.05$ was taken as significant.

RESULTS: Out of 114 participants, 29(25.4\%) paediatricians were already using Telehealth before the COVID-19 pandemic. Whereas, 101(88.6\%) participants used Telehealth during the pandemic. There was an increase in frequency of telehealth use during the pandemic by $72(63.2 \%$ ) paediatricians ( $\mathrm{p}$-value $=0.037)$. Most common factor promoting the use of telehealth during pandemic was 'decreased chance of cross infection and maintenance of social distancing'. Most frequent factor preventing its use was 'lack of confidence on virtual examination findings'.

CONCLUSION: Telehealth provided an effective means of practicing social distancing by the paediatricians without any breach in healthcare provision. However, there are a few factors contributing to hesitancy towards it. Therefore, more platforms must be provided and incentives must be given to paediatricians to promote the use of telehealth.

KEYWORDS: Tele-health, Tele-medicine, COVID-19, Pandemic, Pediatricians, E-education.

\section{INTRODUCTION}

During the most unprecedented times of COVID-19 pandemic, the load on healthcare facilities has increased manyfold worldwide; which very clearly has led to a great change in attitude towards acceptance of the 'telehealth services' during the covid-19 pandemic; despite a lot of resistance to its use in the past ${ }^{[1]}$. The use of telemedicine is being practiced in few developed countries since a long time; and governing bodies like HIPPA and a few others, provide policies for its use ${ }^{[2-3]}$.

The use of telehealth services has also rapidly increased in the field of pediatrics due to several reasons. Most pediatric patients are less critically affected by COVID-19 in comparison to the adults or mostly are asymptomatic carriers. CDC reported less than $1 \%$ infection rate of children $<10$ years in China, same was reported in a study from Italy ${ }^{[4-5]}$. The healthcare professionals constitute about $20 \%$ of the infected population; a study from Iran showed $8.3 \%$ prevalence of covid-19 infection among pediatricians. So, considering that the risk of contracting COVID-19 is more in pediatricians as compared to the pediatric patients, telehealth is an important solution in these times of difficulty ${ }^{[6]}$. Telehealth-literally meaning 'healing at a distance', is a term often used interchangeably with "telemedicine" or

Fatima T, Nasir Z, Jamshaid AA, Ayesha H. COVID-19 pandemic and the use of tele-health by pediatricians and pediatric post graduate residents. Journal of University Medical \& Dental College. 2022;13(1):309-315. 
"e-health"; however, tele-health also covers non-clinical events like administrative meetings, continuing medical education (CME), and physician training.

It allows physicians in evaluation, diagnosis and treatment of patients in distant locations using telecommunications technology. There are three main types of telemedicine; which include store-and-forward, remote monitoring and real-time interactive services. The digital transmission of medical imaging, remote medical diagnosis and treatment, and video consultations with specialists are few examples of telemedicine. Pediatricians can stay updated about new policies, procedures, SOPs and recommendations; participate in medical education, case discussions; monitor and provide care for patients in 'virtual ICUs', get referral consultations and much more via real-time interactive video conferencing ${ }^{[7]}$.

In past, a welcoming attitude had been found towards the acceptance of telemedicine among doctors in Pakistan, despite having average knowledge regarding this subject ${ }^{[8]}$. However, very little native data is available to show its role in pediatric healthcare practices in Pakistan. The rationale for this survey was to study the impact of COVID-19 pandemic on the use of and acceptance of telehealth services among Pakistani pediatricians. This survey intended to study the factors that promote and the barriers that prevent the practicing of telemedicine among pediatricians. The data collected may be helpful in formulating National Telemedicine guidelines for pediatricians; it may revolutionize the current pediatric clinical practices.

\section{METHODOLOGY}

This descriptive cross-sectional study was conducted among the pediatricians of Children Hospital Faisalabad, Allied Hospital and other affiliated hospitals of Faisalabad Medical University, Pakistan. A sample size of 91 was calculated with $95 \%$ confidence of interval and $80 \%$ power of test using WHO calculator ${ }^{[9]}$. After approval by Ethical Review Committee of Faisalabad Medical University (Institutional Review Committee/PHRC/FMU/IRB0006912<OHRP, USA $>$ /Reg. No. 1022/2020-21), participants fulfilling the eligibility criteria were enrolled in the study from August 2020 to January 2021. An invitation to participate in the study was sent to the pediatricians through a self-designed web-based questionnaire using Google Forms. The link for questionnaire was circulated among the pediatricians; mainly through WhatsApp groups and e-mails, which included a total of 357 pediatricians. The inclusion criteria included doctors of both genders; who were general pediatric consultants, pediatric subspecialty consultants, as well as pediatric post-graduate residents. The general practitioners working in pediatric wards were also included. The exclusion criteria included the house officers working in pediatric wards and the doctors who were not related to the field of pediatrics.

Title and the basic purpose of this study were mentioned at the start of the e- questionnaire. Filling the form and its submission was considered as the participant's consent to be included in the study population. Demographic details like age, gender, place of work, current working position were recorded. The 'e- questionnaire' comprised of a total of 22 multiple choice questions. The e-questionnaire was filled and submitted by the participants online either via e-mail or WhatsApp, using whatever was feasible for the participant. For practical purposes, the term "telehealth" in this article was used interchangeably with 'telemedicine' and 'e-health'. Total 114 out of 357 pediatricians filled and submitted the form. All of them fulfilled the eligibility criteria and were included in the study. The data was collected electronically via Google Forms in the form of an Excel file. It was manually entered into and analyzed by SPSS version 20 . Qualitative variables like age groups, gender, place of work and working position were presented as frequency and percentages. Percentages and frequency of paediatricians using telehealth before and during the COVID-19 pandemic were calculated. Chi-square test and Fischer's Exact Test were applied, where applicable. P-value less than 0.05 was taken as statistically significant.

\section{RESULTS}

Out of the 357 pediatricians to which the form was circulated, 114 pediatricians filled and submitted the form. All of them fulfilled the eligibility criteria and the data submitted by them was included in the study and analyzed. Total 29(25.4\%) paediatricians responded that they were already familiar with, and were using Telehealth in one form or the other, before the COVID-19 pandemic in Pakistan (i.e., before 11th March 2020). Whereas, 101(88.6\%) participants responded that they used Telehealth during the pandemic. Out of these 101 telehealth users, there were $72(63.2 \%)$ paediatricians who started using telehealth during the pandemic. There was a significant increase in the use of telehealth among paediatricians during the pandemic $(p$-value $=0.037)$. There were total 13 respondents, who didn't use telehealth either before or after the pandemic (Table-I).

Table-III shows the details of information shared by the parents/patients during the telehealth consultation. It shows the percentage of types of ailments for which the consultation was sought as well as the type of information shared by the parents. It also shows the purpose of use of telehealth by the paediatric practitioners and the software preference by them. The top three ailments requiring teleconsultation by parents included respiratory tract infections $73(64 \%)$, diarrhoea 55 (48.2\%) and febrile illnesses 47 (41.2\%). The most preferred software used for teleconsultation by the pediatricians were WhatsApp 84 (73.7\%) and Zoom 43 (37.7\%).

Pediatricians were asked regarding the factors which they considered favourable for the use, as well as, those preventing the use of telehealth by them Table-IV.

Out of 114 pediatricians,14(12.3\%) responded that they used to gain financial benefit by telehealth consultations. Regarding the "reliability of information shared by 
Fatima T, Nasir Z, Jamshaid AA, et al.,

Table-I: Pediatricians using Telehealth Before and During pandemic $(n=114)$.

\begin{tabular}{cccc}
\hline & & Pediatricians using Telehealth During Pandemic & p-value* \\
\hline & & Yes n (\%) & No \\
Pediatricians using Telehealth & Yes & $29(28.7)$ & $0(0)$ \\
Before Pandemic & No & $72(71.3)$ & $13(100)$ \\
Total & & $101(88.6)$ & $13(11.4)$
\end{tabular}

*by applying Fischer's Exact test; n=total no. of pediatricians

Table-II: Demographic details of the study population and Comparison of Telehealth use Before and During the Pandemic ( $n=114)$.

\begin{tabular}{|c|c|c|c|c|c|c|c|}
\hline \multicolumn{2}{|c|}{ Demographic Characteristics } & \multicolumn{3}{|c|}{ Use of Telehealth before Pandemic } & \multicolumn{3}{|c|}{ Use of Telehealth during Pandemic } \\
\hline & Total n(\%) & $\begin{array}{c}\text { Yes } \\
n(\%)\end{array}$ & $\begin{array}{l}\text { No } \\
\mathbf{n}(\%)\end{array}$ & p-value & $\begin{array}{c}\text { Yes } \\
\mathbf{n}(\%)\end{array}$ & $\begin{array}{l}\text { No } \\
\mathbf{n}(\%)\end{array}$ & p-Value* \\
\hline \multicolumn{8}{|l|}{ Gender } \\
\hline Male & $27(23.7)$ & $6(20.7)$ & $21(24.7)$ & & $23(22.8)$ & $4(30.8)$ & \\
\hline Female & $87(76.3)$ & $23(79.3)$ & $64(75.3)$ & 0.660 & $78(77.2)$ & $9(69.2)$ & 0.523 \\
\hline Total & & & & & $101(88.6)$ & $13(11.4)$ & \\
\hline \multicolumn{8}{|l|}{ Age Group (years) } \\
\hline $21-30$ & $55(48.2)$ & $13(44.8)$ & $42(49.4)$ & & $52(51.5)$ & $3(23.1)$ & \\
\hline $31-40$ & $55(48.2)$ & $13(44.8)$ & $42(49.4)$ & & $45(44.6)$ & $10(76.9)$ & \\
\hline $41-50$ & $03(2.6)$ & $2(6.9)$ & $1(1.2)$ & 0.128 & $3(3)$ & $0(0)$ & 0.200 \\
\hline $51-60$ & $01(0.9)$ & $1(3.4)$ & $0(0)$ & & $1(1)$ & $0(0)$ & \\
\hline Total & & $29(25.4)$ & $85(74.6)$ & & $101(88.6)$ & $13(11.4)$ & \\
\hline \multicolumn{8}{|l|}{ Place of Work } \\
\hline $\begin{array}{c}\text { Tertiary Care/Teaching } \\
\text { Hospital }\end{array}$ & $95(83.3)$ & $24(82.8)$ & $71(83.5)$ & & $87(86.1)$ & $8(61.5)$ & \\
\hline DHQ & $10(8.8)$ & $2(6.9)$ & $8(9.4)$ & & $7(6.9)$ & $3(23.1)$ & \\
\hline BHU & $04(3.5)$ & $1(3.4)$ & $3(3.5)$ & 0.905 & $4(4)$ & $0(0)$ & 0.036 \\
\hline Private Clinic & $05(4.4)$ & $2(6.9)$ & $3(3.5)$ & & $3(3)$ & $2(15.4)$ & \\
\hline Total & $29(25.4)$ & $85(74.6)$ & & & $101(88.6)$ & $13(11.4)$ & \\
\hline \multicolumn{8}{|l|}{ Work Position } \\
\hline Consultant General Pediatrics & $24(21.1)$ & $3(10.3)$ & $21(24.7)$ & & $18(17.8)$ & $6(46.2)$ & \\
\hline $\begin{array}{c}\text { Consultant Pediatric } \\
\text { Subspecialty }\end{array}$ & $17(14.9)$ & $7(24.1)$ & $10(11.8)$ & & $15(14.9)$ & $2(15.4)$ & \\
\hline $\begin{array}{l}\text { General Practitioner } \\
\text { (practicing pediatrics) }\end{array}$ & $45(39.5)$ & $10(34.5)$ & $18(21.2)$ & 0.086 & $27(26.7)$ & $1(7.7)$ & 0.117 \\
\hline Pediatric Residents & $28(24.6)$ & $9(31)$ & $36(42.4)$ & & $41(40.6)$ & $4(30.8)$ & \\
\hline Total & $29(25.4)$ & $85(74.6)$ & & & $101(88.6)$ & 13(11.4) & \\
\hline
\end{tabular}

n=total no. of pediatricians; *by applying Chi-Square and Fischer's Exact Tests, where applicable

the parents" during teleconsultation, only 21(18.4\%) pediatricians responded that they considered the information reliable, whereas, 63(55.3\%) considered the information to be only "partially" reliable. Regarding "satisfaction of pediatricians with the care provided by the them to patients via teleconsultation", 34(29.8\%) pediatricians responded that they were "satisfied" whereas 55(48.2\%) responded that they were only "partially satisfied". However, regarding the "satisfaction of their patients/parents with teleconsultation", $52(45.6 \%)$ of them responded that their patients were "satisfied", whereas, 40(35.1\%) responded that the parents were "partially satisfied".
Total 41(36\%) pediatricians recommended the use of telehealth whereas $45(39.5 \%)$ recommended its use "partially". Answering the questions regarding stress due to telehealth use, $37(32.5 \%)$ told that they felt "stress out", whereas 44(38.6\%) said they felt "partially stressed". Among the respondents, $24(21.1 \%)$ pediatricians reported headache, $24(21.1 \%)$ reported lack of sleep, 17 (14.9\%) experienced visual problems, $7(6.1 \%)$ reported backache, whereas 3 $(2.6 \%)$ reported certain other health issues. Table-V shows a comparison of range of patients given teleconsultations before and during pandemic and the number of patients requiring admissions via teleconsultations. 
Table-III: Details of the telehealth consultations provided by the pediatricians $(n=114)$.

\begin{tabular}{|c|c|c|c|}
\hline \multicolumn{4}{|c|}{ Consultation sought by parents for the type of ailment $n(\%)$} \\
\hline Respiratory Tract Infections & $73(64)$ & Renal & $3(2.6)$ \\
\hline Diarrhea & $55(48.2)$ & Cardiac & $6(5.3)$ \\
\hline Febrile Illness & $47(41.2)$ & GI/Liver & $11(9.6)$ \\
\hline Infectious Disease & $30(26.3)$ & Dermatology & $15(13.2)$ \\
\hline Neonatal & $24(21.1)$ & Neurology & $6(5.3)$ \\
\hline \multicolumn{4}{|c|}{ Type of Information shared by the parents n (\%) } \\
\hline History & $90(78.9)$ & Physical Examination & $17(14.9)$ \\
\hline Pictures & $57(50)$ & Videos & $36(31.6)$ \\
\hline Investigations & $60(52.6)$ & Treatment advised & $52(45.6)$ \\
\hline \multicolumn{4}{|c|}{ Purpose for Telehealth Consultation by the Pediatricians n (\%) } \\
\hline Patient clinical consultation & $58(50.9)$ & Referral appointments & $12(10.5)$ \\
\hline Patient Follow-up & $22(19.3)$ & Medical Education & $36(31.6)$ \\
\hline Case Discussions & $33(28.9)$ & Knowledge sharing via video-conferencing & $40(35.1)$ \\
\hline \multicolumn{4}{|c|}{ Software Used for Telehealth by the Pediatricians n (\%) } \\
\hline Whatsapp & $84(73.7)$ & Professional Medical Online Portals & $14(12.3)$ \\
\hline Facebook/Messenger & $14(12.3)$ & Socrative & $2(1.8)$ \\
\hline Facetime & $6(5.3)$ & Google Meet/Classroom & $6(5.3)$ \\
\hline Zoom & $43(37.7)$ & Webex & $6(5.3)$ \\
\hline Skype & $3(2.6)$ & Institution based services & $6(5.3)$ \\
\hline Youtube & $26(22.8)$ & Others & $2(1.8)$ \\
\hline
\end{tabular}

Table-IV: Factors promoting and preventing Telehealth use among pediatricians $(n=114)$.

\begin{tabular}{|c|c|}
\hline \multicolumn{2}{|c|}{ Factors promoting the use of Telehealth use in pandemic $n(\%)$} \\
\hline Less patient physical interaction & $61(53.5)$ \\
\hline Decreased chances of cross contamination/transmission & $78(68.4)$ \\
\hline Social distancing & $78(68.4)$ \\
\hline Ease to communicate & $33(28.9)$ \\
\hline Time saving & $38(33.3)$ \\
\hline Helps in working from home & $46(40.4)$ \\
\hline Prevents injudicious use of PPE & $45(39.5)$ \\
\hline \multicolumn{2}{|c|}{ Factors acting as a barrier to the use of Telehealth in pandemic $n(\%)$} \\
\hline Time consuming & $18(15.8)$ \\
\hline Consultation out of duty hours causing extra stress & $53(46.5)$ \\
\hline Lack of confidence in 'virtual' examination findings & $69(60.5)$ \\
\hline Lack of reliable information by parents/caregivers & $66(57.9)$ \\
\hline Lack of parents'/care-giver's satisfaction & $34(29.8)$ \\
\hline Parents'/care-giver's reluctance to participate & $13(11.4)$ \\
\hline Breach of privacy & $6(5.3)$ \\
\hline Lack of appropriate IT availability & $26(22.8)$ \\
\hline Lack of appropriate IT knowledge/troubleshooting support & $22(19.3)$ \\
\hline No/inadequate financial gain & $25(21.9)$ \\
\hline \multicolumn{2}{|c|}{ Recommendations for promoting use of Telehealth by the Pediatricians n (\%) } \\
\hline Good/adequate financial gains & $25(21.9)$ \\
\hline Utilization for patients' initial visits & $25(21.9)$ \\
\hline Utilization for patients' follow up & $53(46.5)$ \\
\hline Utilization for specialist consultation/referral & $24(21.1)$ \\
\hline Utilization for the purpose of medical education & $50(43.9)$ \\
\hline Utilization for practicing social distancing and less patient exposure & $65(57)$ \\
\hline Formation of National Telemedicine guidelines & $34(29.8)$ \\
\hline
\end{tabular}


Table-V: Range of teleconsultations per week by pediatricians $\mathbf{n}(\%)$.

\begin{tabular}{cccccc}
\hline Number of Teleconsultations & $\begin{array}{c}\mathbf{0 - 5} \\
\text { Consultations }\end{array}$ & $\begin{array}{c}\mathbf{6 - 1 0} \\
\text { Consultations }\end{array}$ & $\begin{array}{c}\mathbf{1 1 - 1 5} \\
\text { Consultations }\end{array}$ & $\begin{array}{c}\mathbf{1 6 - 2 0} \\
\text { Consultations }\end{array}$ & $\begin{array}{c}>\mathbf{2 0} \\
\text { Consultations }\end{array}$ \\
\hline Before Pandemic & $53(46.5)^{*}$ & $11(9.6)$ & $1(0.9)$ & $0(0)$ & $0(0)$ \\
During Pandemic & $35(30.7)$ & $30(26.3)$ & $9(7.9)$ & $7(6.1)$ & $5(4.4)^{* *}$ \\
\hline $\begin{array}{c}\text { Patients requiring admission via } \\
\text { teleconsultation during pandemic }\end{array}$ & $73(64)$ & $8(7)$ & $2(1.8)$ & $1(0.9)$ & $1(0.9)$
\end{tabular}

*Teleconsultations given by pediatricians were in lower range before the pandemic, ranging mostly from $0-5$ consultations per week

**Whereas, increased number of consultations can be seen during the pandemic reaching up to $>20$ teleconsultations per week

\section{DISCUSSION}

The world has seen the progressive appraisal and evolution of telehealth with the emergence of COVID-19 pandemic, although the digital approach to the health sector was lying dormant prior to the pandemic ${ }^{[10]}$. There has been a fall in paediatricians' consultations given on outpatient basis in hospitals in Cameroon; from $60.4 \%$ before the pandemic to $9.9 \%$ during the pandemic $(\mathrm{p}<0.05)$. Vice versa, the use of telehealth consultations has increased to $23.8 \%$ during pandemic from $0 \%$ before the pandemic $(\mathrm{p}<0.05)$ [9]. Quite similar results were found in our study too with most of the paediatricians responding with the uptake of telehealth during the pandemic; and many of them found it really advantageous. The digital healthcare support for the paediatric patients included; psychosocial support, advice for medicine adherence and self-management, preventive behaviours as well as peer support in addition to telemedicine services ${ }^{[1]}$.

Telehealth although not has been given any formal national guidelines in our country, but seeing its benefits in the developed countries, many universities in Pakistan have used it as their institutional policy to decrease the outpatient burden during the COVID-19 pandemic, by developing Telemedicine centres ${ }^{[12-13]}$. These centres provided round the clock guidance to patients in far-off areas, who could not travel due to country-wide lockdown and fear of getting infected while travelling in public transports and mass crowding in hospitals.

A myriad of patients belonging to paediatric subspecialities have benefitted from the telehealth services, including paediatric pulmonology, paediatric rheumatology, paediatric neurology, paediatric endocrinology and diabetes, paediatric gastroenterology; just to name a few ${ }^{[14-19]}$. The digital tools like digital stethoscopes, otoscopes, electrocardiograms, pulse oximeters have even helped physicians monitor patients at far away areas [11]. Not only this, but the technological advances with a number of new software have opened up new horizons of learning for medical students as well as physicians and post graduate residents. E-learning in form of online webinars for physician training has been very helpful in continuing medical education in these unpredictable times ${ }^{[20]}$. Medical students have successfully completed their education via online classes, which has saved them from the hazards of lagging behind in their education.
The digital health interventions are currently facing challenges in our country; as per a recent SWOT analysis report including 51 digital health projects, the hurdles in the implementation of health system digitalisation included our populations' inability to use technology (21\%), high budget costs of these projects $(16 \%)$ and privacy concerns $(12 \%)$ [21].

There are other limitations to telehealth too; mostly due to lack of financial benefits to the physicians and lack of regulatory bodies ${ }^{[22]}$. During the COVID-19 pandemic, many specialists including pediatricians, are providing telemedicine services voluntarily and free of cost in the developing countries ${ }^{[23]}$. Technology has helped a lot in development of virtual healthcare software, like the application 'WeChat' which helped a lot in China for providing virtual health care services, during the pandemic ${ }^{[23]}$. By ensuring adequate payment, employment can be provided to the unemployed health care professionals; in this way, they may share the burden of already loaded health facilities, by providing telehealth services to the 'cold cases. However, many pediatricians do not consider telemedicine as an alternative for the traditional medical examination, considering it as one of the drawbacks of telemedicine. Same can be seen from the data obtained in our study. As Pakistan is still struggling with covid-19 and proper knowledge and awareness is necessary at all levels [24-25]. Therefore, telehealth is an important intervention that can be done in combating this disease effectively.

\section{CONCLUSION}

Telehealth is a beneficial aspect of technology that has introduced new concepts of patient care and e-learning in the field of medicine and health. The significant upsurge in the uptake of telehealth services by pediatricians during the pandemic as shown by our study has opened new horizons for patient care methods. The concept can be helpful for the healthcare workers as well as the pediatric patients; saving their time, travel expenses and loss of education. The use of telehealth should be further promoted, not only for the healthcare professionals but also for the general public. Its use should be promoted by making formal guidelines for Telehealth use on a national level as in many developed countries and by providing technical and financial support to the health care workers for its use. 
ACKNOWLEDGEMENT: To all pediatricians and residents who have participated in the study.

CONFLICT OF INTEREST: None.

GRANT SUPPORT \& FINANCIAL DISCLOSURE: None.

\section{REFERENCES:}

1. Chauhan V, Galwankar S, Arquilla B, Garg M, Di Somma S, El-Menyar A, et al. Novel coronavirus (COVID-19): Leveraging telemedicine to optimize care while minimizing exposures and viral transmission. Journal of emergencies, trauma, and shock. 2020;13(1):20. Doi: 10.4103/JETS.JETS_32_20

2. Telemedicine: Opportunities and Developments in Member States: Report on the Second Global Survey on eHealth 2009 (Global Observatory for eHealth Series, Volume 2).2010. World Health Organization. ISBN: 978-92-4-156414-4. Available online at: http://www. who.int/goe/publications/goe_telemedicine_2010.pdf

3. Patel PD, Cobb J, Wright $\overline{\mathrm{D}}$, Turer RW, Jordan T, Humphrey A, et al. Rapid development of telehealth capabilities within pediatric patient portal infrastructure for COVID-19 care: barriers, solutions, results. Journal of the American Medical Informatics Association. 2020;27(7):1116-1120. Doi:10.1093/jamia/ocaa065

4. Lu X, Zhang L, Du H, Zhang J, Li YY, Qu J, et al. SARS-CoV-2 infection in children. New England Journal of Medicine. 2020;382(17):1663-1665. Doi: 10.1056/NEJMc2005073.

5. Cruz AT, Zeichner SL. COVID-19 in Children: Initial Characterization of the Pediatric Disease. Paediatrics.2020;145(6): e20200834. Available form: Doi:10.1542/peds.2020-0834

6. Rezaei N. Letter to the Editor COVID-19 affects healthy pediatricians more than pediatric patients. Infection Control \& Hospital Epidemiology. 2020;41(9): 11061107 Available form: Doi: 10.1017/ice.2020.139.

7. Wosik J, Fudim M, Cameron B, Gellad ZF, Cho A, Phinney D, et al. Telehealth transformation: COVID-19 and the rise of virtual care. Journal of the American Medical Informatics Association. 2020;27(6):957-962. Doi:10.1093/jamia/ocaa067

8. Ashfaq A, Memon SF, Zehra A, Barry S, Jawed H, Akhter M, et al. Knowledge and Attitude Regarding Telemedicine Among Doctors in Karachi. Cureus. 2020;12(2):e6927. Doi: 10.7759/cureus.6927.

9. Enyama D, Chelo D, Njinkui DN, Kouam JM, Puepi YF, Nkwele IM, et al. Impact of the COVID-19 pandemic on pediatricians' clinical activity in Cameroon. Archives de Pédiatrie. 2020;27(8):423-427. Doi: 10.1016/j. arcped.2020.09.004

10. Hageman JR. The Emergence of Pediatric Telehealth as a result of the COVID-19 pandemic. Pediatric Annals. 2020; 29(70): e283-284. Available form: Doi: $10.3928 / 19382359-20200626-01$
11. Badawy SM, Radovic A. Digital Approaches to Remote Pediatric Health Care Delivery during the COVID-19 Pandemic: Existing Evidence and a call for Further Research. JMIR Pediatrics Parenting. 2020; 3(1): e20049. Doi:10.2196/20049

12. Waseem M, Aziz N. Role of social media in diagnosis and management of COVID-19; An Experience of a Pulmonologist. Annals of King Edward Medical University. 2020; 26(Special Issue): 233-234. Available form: https:/www.annalskemu.org/journal/index.php/ annals/article/view/3644

13. Shaukat A, Saleem MA, Ali G, Riaz SA, Danish M. Role of Telemedicine in Management of Surgical Patients During COVID-19 Lockdown: A Solution to Reduce Footprints in Surgical Outpatient Clinics. Annals of King Edward Medical University. 2020; 26(Special Issue): 135-139. Available form: https:// www.annalskemu.org/journal/index.php/annals/article/ view/3624

14. Onofri A, Pavone M, De Santis S, Verrillo E, Caggiano $\mathrm{S}$, Ullmann $\mathrm{N}$, et al. Telemedicine in children with medical complexity on home ventilation during the COVID-19 pandemic. Pediatric Pulmonology. 2021. Doi:10.1002/ppul.25289

15. Balmuri N, Onel KB. Glitches in the utilization of telehealth in pediatric rheumatology patients during the COVID-19 pandemic. Pediatric Rheumatology. 2020;18(1):1-3. Doi:10.1186/s12969-020-00477-y

16. Ben-Pazi H, Beni-Adani L, Lamdan R. Accelerating Telemedicine for Cerebral Palsy During the COVID-19 Pandemic and Beyond. Frontiers in Neurology. 2020. 11:746. Doi: 10.3389/fneur.2020.00746

17. Chowdhury D, Hope KD, Arthur LC, Weinberger SM, Ronai C, Johnson JN, et al. Telehealth for Pediatric Cardiology Practitioners in the Time of COVID-19. Pediatric Cardiology. 2020; 41:1081-1091. Available form: Doi:10.1007/s00246-020-02411-1

18. Mallon D, Pohl JF, Phatak UP, Fernandes M, Rosen JM, Lusman SS, et al. Impact of COVID-19 on Pediatric Gastroenterology Fellow Training in North America. Journal of Pediatric Gastroenterology and Nutrition. 2020; 71(1): 6-11 Available form: Doi: 10.1097/ MPG.0000000000002768.

19. Elbarbary NS, Santos TJ, Beaufort C, Agwu JC, Calliari LE, Scaramuzza AE, et al. COVID-19 outbreak and pediatric diabetes: Perceptions of health care professionals worldwide. Pediatric Diabetes. 2020: 1083-1092. Doi:10.1111/pedi.13084

20. Bhatti D, Zafar W, Rafiq S. Challenges as Opportunities: Adapting Tele-Education for Physicians Collaborative Response to COVID-19 Pandemic. Annals of King Edward Medical University. 2020;26(Special Issue): 112-114. Available from: https://annalskemu.org/ journal/index.php/annals/article/view/3617 
21. Kazi AM, Qazi SA, Ahsan N, Khawaja S, Sameen F, Saqib M, et al. Current challenges of digital health interventions in Pakistan: mixed methods analysis. Journal of Medical Internet Research. 2020;22(9):e21691.

22. Berg EA, Picoraro JA, Miller SD, Srinath A, Franciosi JP, Hayes CE, et al. COVID-19-A guide to rapid implementation of telehealth services: A playbook for the pediatric gastroenterologist. Journal of Pediatric Gastroenterology and Nutrition. 2020;70(6):734.

23. Webster P. Virtual health care in the era of COVID-19. Lancet. 2020.395;10231: 1180-1181. Available form: Doi:10.1016/S0140-6736(20)30818-7

24. Tariq S, Tariq S, Baig M, Alam SS. Adequacy of preventive measures, awareness, and attitude regarding the COVID-19 pandemic among university pharmacy students. Pharmacy Education. 2020:283-289.

25. Tariq S, Tariq S, Baig M, Saeed M. Knowledge, Awareness, and Practices Regarding the Novel Coronavirus Among a Sample of a Pakistani Population: A Cross-Sectional Study. Disaster Medicine and Public Health Preparedness. 2020:1-6.

\section{Author's Contribution:}

Tehreem Fatima: Literature review, manuscript write up data acquisition and analysis.

Zaib Nasir: Acquisition of data.

AbdulAhad Jamshaid: Acquisition of data.

Hina Ayesha: Supervision and final review of the manuscript.

Submitted for publication: 04-07-2021

Accepted after revision: 17-02-2022

\section{ANNEXURE-I \\ STROBE FLOW DIAGRAM}

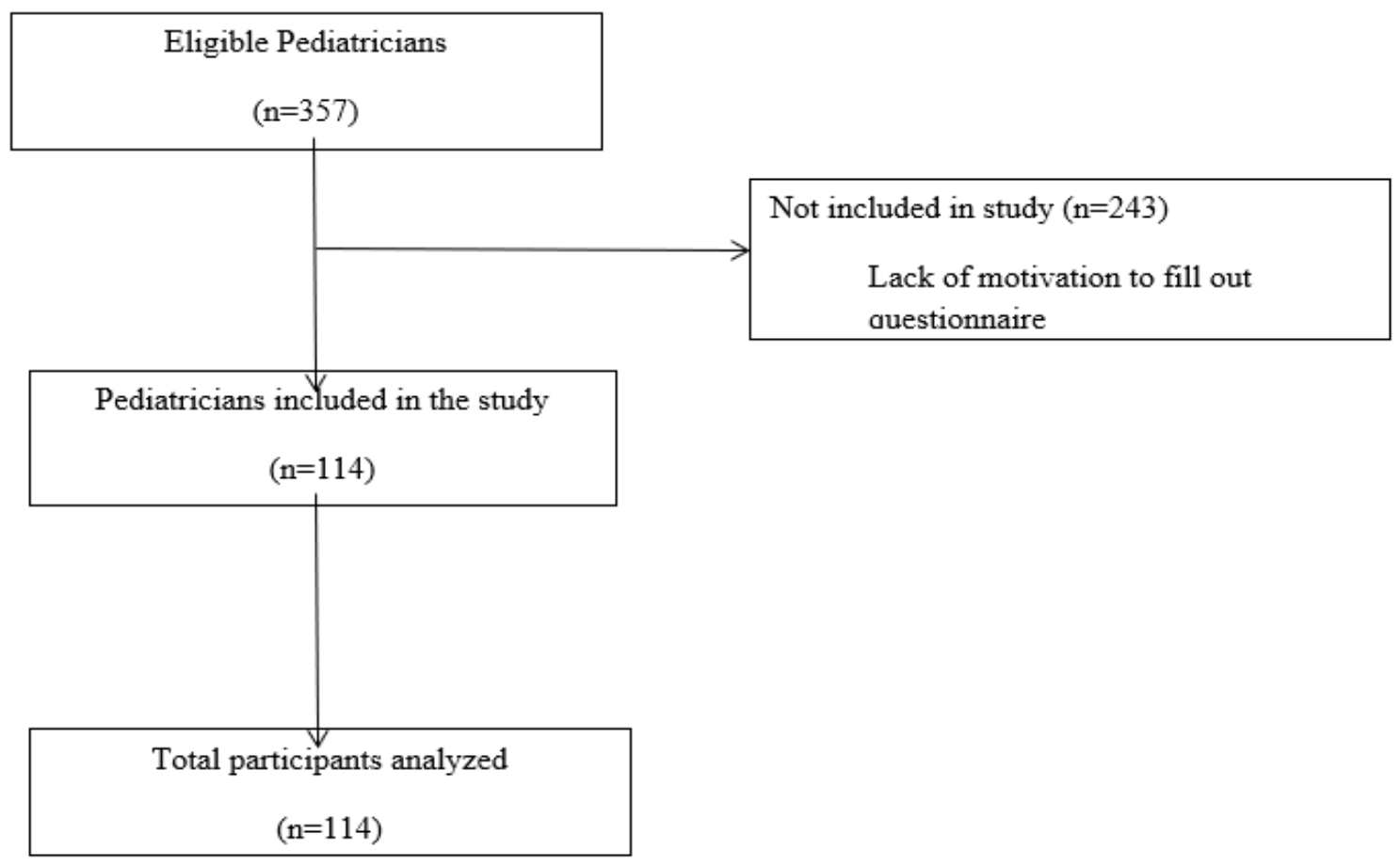

